\title{
Mulheres professoras: autoras de suas próprias histórias
}

\author{
Mujeres maestras: autores de sus propias historias
}

Women teachers: authors of their own stories

Maria Betânia e Silva ${ }^{1}$

\begin{abstract}
Resumo
O texto objetiva refletir sobre mulheres profissionais do campo das Artes Visuais, bem como os significados, as dificuldades no cotidiano da profissão e os desejos futuros. Dentro do território das investigações qualitativas se insere na perspectiva metodológica das histórias de vida que contemplam as narrativas de investigação profissional. Mostra narrativas tecidas a partir das próprias memórias e experiências vividas e adquiridas, ao longo dos anos de trabalho. Suas narrativas se apresentam como possibilidades de dar visibilidade a essas mulheres, a fim de compreender/apreender os sentidos que estas atribuem à profissão.
\end{abstract}

Palavras-chave: artes visuais; formação; memórias; mulheres.

\section{Resumen}

El texto tiene como objetivo reflexionar sobre las mujeres profesionales en el campo de las Artes Visuales, así como los significados, las dificultades en la vida cotidiana de la profesión y los deseos futuros. Dentro del territorio de las investigaciones cualitativas, se inserta en la perspectiva metodológica de las historias de vida que contemplan las narrativas de la investigación professional. Muestra narrativas tejidas de los recuerdos y experiencias vividas y adquiridas, a lo largo de los años de trabajo. Sus narrativas se presentan como posibilidades para dar visibilidad a estas mujeres, con el fin de entender/comprender los significados que atribuyen a la profesión.

Palabras clave: artes visuales; formación; memórias; mujeres.

\begin{abstract}
The text aims to reflect on professional women in the field of Visual Arts, as well as the meanings, difficulties in the daily life of the profession and future desires. Within the territory of qualitative investigations is part of the methodological perspective of life stories that contemplate the narratives of professional research. It shows narratives woven from the memories and experiences lived and acquired, throughout the years of work. Their narratives are presented as possibilities to give visibility to these women, in order to understand/grasp the meanings they attribute to the profession.
\end{abstract}

Keywords: memories; training; visual arts; women.

\footnotetext{
${ }^{1}$ Doutorado em Educação pela UFMG; Professora da Graduação e do Programa Associado de Pós-graduação em Artes Visuais UFPE/UFPB; Recife, Pernambuco, Brasil; mbsppgav@gmail.com.
} 


\section{Introdução}

O que significa ensinar Artes Visuais? Quais as maiores dificuldades na docência em Artes Visuais? Se pudesse começar tudo de novo que profissão escolheria? Qual seu maior desejo diante do futuro? Esses foram alguns dos cerca de 60 questionamentos respondidos, individualmente, por oito professoras ${ }^{2}$ universitárias em três etapas distintas que envolveram a infância, a adolescência e a vida adulta. $\mathrm{O}$ estudo faz parte de uma pesquisa mais ampla que objetiva compreender o que a memória ressalta sobre trajetórias de formação em Artes Visuais e como se constroem as narrativas pessoais profissionais.

Com o campo de pesquisa localizado na cidade do Recife os resultados da investigação vêm sendo divulgados, paulatinamente, em eventos científicos. Debruçamo-nos sobre as aproximações e contatos com a Arte e experiências artísticas que essas mulheres tiveram durante a infância ressaltando o papel da memória e seus disparadores e dispositivos (SILVA, 2017). Centramo-nos no período da adolescência ressaltando as aulas de Arte que tiveram e as marcas de encontros com a Arte buscando compreender as experiências que contribuíram para suas escolhas e atuação profissionais (SILVA, 2018). Voltamo-nos para o entendimento de como se deu a escolha do curso superior e da carreira docente (SILVA, 2019).

Esse artigo direciona sua reflexão para os significados do ser docente, as dificuldades no cotidiano da profissão e os desejos futuros dessas mulheres profissionais do campo das Artes Visuais, autoras de suas histórias.

Como investigação qualitativa, que procura compreender como e por que os fenômenos se desenvolvem e as representações que se fazem deles, os estudos qualitativos mostram a diversidade dos pontos de vista, captam invisibilidades, censuras e silenciamentos nas construções narrativas (POUPART; DESLAURIERS; GROULX; LAPERRIÈRE; MAYER; PIRES, 2008). Dentro do território das investigações qualitativas se insere, mais especificamente, na perspectiva metodológica das histórias de vida que contemplam as narrativas de investigação profissional (DELORY-MOMBERGER, 2015) tecendo diálogos com os conceitos de memória, narrativa autobiográfica.

Ao aprofundar os trajetos percorridos pelas professoras percebemos que o encantamento, a magia, a imaginação estiveram presentes em seus percursos como propulsores do refinamento do sensível e do exercício dos sentidos. Foi na família que a

\footnotetext{
2 As colaboradoras de nossa investigação são identificadas pela principal qualidade que elas se atribuem: Sobrevivência; Habilidade Interpessoal; Feliz; Pró-ativa; Positividade; Perseverança; Liberdade; Estudiosa.
} 
maioria delas recebeu o impulso e estímulo inicial para a Arte. Um membro, pelo menos, tinha algum envolvimento com a Arte, o pai, a mãe, um tio/a, um primo que tocavam algum instrumento, faziam trabalhos manuais, pintavam, dançavam ou criavam cenas teatrais etc.

Suas experiências escolares mostram desde a presença de atividades manuais direcionadas para a formação e atuação da mulher no lar com exercícios reprodutores e repetitivos, como também a presença das festas escolares e experimentos mais direcionados ao campo da Arte que passaram a fazer parte do cotidiano de aprendizagem escolar com materiais, técnicas e campos distintos como o teatro, a música e as artes visuais.

Durante a adolescência e juventude o contato e a frequência aos espaços culturais foram fatores fundamentais para ampliar seus repertórios visuais, culturais e artísticos que contribuíram para a dilatação dos sentidos e o contato direto com lugares e obras de Arte em suas vidas na fase adulta. Mas, outros espaços socioculturais também se apresentaram como lugares que lhes atraíam para vivenciar o coletivo e desenvolver o sentimento de pertencimento social destacando a frequência a bibliotecas, teatros, centro culturais, igreja, rua, clube, piscina, praia, praça.

Para essas professoras a leitura, ida ao teatro, cinema, exposições, a prática de atividades manuais e de esporte aparecem como ações preferidas nos momentos de ócio. Embora, a história de cada uma apresente percursos distintos de acesso aos bens culturais e experiências com a Arte, é possível perceber uma possível influência e relação na escolha profissional oriunda da primeira célula social, a família, corroborando com os estudos de Bueno (2007).

Em seus processos de organização da prática docente priorizam a seleção de conteúdos, adequação ao plano de ensino, consulta aos estudantes a partir de suas necessidades dialogando com Freire (1996) sobre a tomada de consciência do inacabamento entendendo sempre que se pode ir além do condicionamento a que somos submetidos e reforçam o dito por Cordeiro; Melo; Ramos (2013) sobre a importância da ressignificação do sentido de ensinar.

Diante desse preâmbulo, nos direcionamos aos questionamentos introdutórios desse texto.

\section{O que significa ensinar Artes Visuais?}

Ao realizar esse questionamento às colaboradoras de nossa investigação intencionamos captar aquilo que, em geral, pouco ouvimos dos profissionais sobre os significados pessoais em seus campos de atuação. Assim, Canton (2009a) nos relembra que as 
palavras e seus sentidos, a memória, a herança e a tradição passam a ser revalorizados num mundo em que se inunda continuamente de imagens fosforescentes veiculadas pelas mídias.

Contar histórias se transforma em um jeito de se aproximar do outro e na troca entre ambos, de gerar sentido em si mesmo e no outro, afirma a autora. E, nesse sentido, procuramos ressignificar o mundo por intermédio das histórias. Vale salientar que os (re)significados estão diretamente vinculados às referências de vida de cada um, aos repertórios pessoais.

Assim, para a professora Positividade ensinar Artes Visuais "significa proporcionar formas mais amplas de ler o mundo, de entender os tensionamentos por outros vieses, de refletir a partir de outros estímulos, de formar sujeitos humanos sensíveis, estéticos, artísticos".

"Fazer o que amo conhecendo pessoas e falando sobre coisas maravilhosas criadas pelos homens, refletindo, tornando o mundo melhor de se viver" foi o registro realizado pela professora Perseverança.

Com o foco na ação transformadora a professora Liberdade ressalta:

Arte carrega a potência de transformação. Ensinar arte é propiciar experiências e reflexões transformadoras para as pessoas, uma grande responsabilidade, portanto. Porém, a direção dessas transformações não está no controle do/a arte/educador/a, pois não acredito em educação como processo de controle, embora o sistema educacional seja todo formatado como reprodução e controle. Tento tensionar o sistema para gerar experiências de autonomia e transformação dos sujeitos, dentro dos limites possíveis. Existem outras qualidades que vejo no ensino de Arte como ampliação de referencial cultural, problematização da realidade, aprofundamento do sensível. Porém, todas relacionadas ao potencial transformador como síntese de um propósito maior e resultado concreto, pois a própria ação artística possibilita descoberta de potenciais criadores dos sujeitos, de outras formas de lidar com a realidade, de transformar a si próprio e transformar a realidade à sua volta. Transformar, por exemplo, um pedaço de papel branco em um desenho significativo, com uma carga subjetiva, simbólica e de comunicação. O tempo todo a autoestima dos sujeitos é renovada quando percebem essas potencialidades de transformação (Depoimento da professora Liberdade).

Diante dos posicionamentos apresentados pelas professoras, Domingo (2015, p.38) nos ajuda a refletir sobre suas falas trazendo à tona que educativamente aspiramos a algo que imaginamos de um modo inconcreto, que não tem forma. O que desejamos, afirma o autor, "es que nuestros estudiantes, nuestras hijas e hijos sean autores de sí mismos, se formen, esto es, se den forma a sí mismos. Por eso, la educación es algo paradójicamente intangible”.

Para Pró-ativa ensinar Artes Visuais

está ligado a relacionar novas aprendizagens com as experiências vividas. Trazer discussões de aspectos históricos aos fatos que acontecem na atualidade. 
Proporcionar reflexões críticas e mudanças na maneira de olhar e entender as situações. Ensinar arte é ensinar a ver o mundo com inúmeras lentes (Depoimento da professora Pró-ativa).

A Arte é fundamental na formação humana, ressalta a professora Feliz. E continua dizendo que para termos uma sociedade mais crítica, ao mesmo tempo, mais justa e democrática, a Arte nos possibilita esse olhar para nós e para o outro. A professora acrescenta "para que a Arte se torne parte do cotidiano das pessoas (essa é minha luta) devemos ter um ensino de Arte democrático em todas as salas de aula, com professores e professoras com uma formação docente crítica, artística, metafórica e cultural”. E finaliza dizendo que para ela, ensinar Arte tem o significado de tê-la como objeto de estudo em todos os níveis educacionais como uma política pública.

Os trechos narrativos construídos pelas professoras se conectam ao que destaca Domingo (2015, p.57) que "la narración, por su propia naturaleza, pone en juego situaciones con un potencial pedagógico. Una narración pone en relación personajes y acontecimentos, vidas concretas y experiencias que se viven".

Mais três professoras apresentaram suas respostas de forma sucinta. A professora Habilidade Interpessoal afirma que a arte é um assunto muito prazeroso e lhe traz muita satisfação em estudá-la e falar sobre ela. A professora Sobrevivência, por sua vez, explicita que é um sonho realizado transmitir um conhecimento que considera importante. Por fim, Estudiosa registra que ensinar Artes Visuais para ela "pode proporcionar para o outro o desvelar um mundo, um mundo novo. Poder dar condições do exercício da criatividade, do conhecimento do mundo consigo mesmo. Deixar que o outro estabeleça novas ligações, novos contatos".

Diante desses significados de ensinar Artes Visuais apresentados por essas mulheres podemos observar que as narrativas registradas foram tecidas a partir do debruçar-se sobre as próprias memórias e experiências vividas por elas ao longo de suas trajetórias de atuação profissional. Memórias e experiências ressignificadas que se materializaram ao serem narradas. Assim, Sampaio e Ribeiro (2015) trazem para o diálogo a importância de que narrar uma experiência demanda refletir sobre um acontecimento, revivê-lo, e isso tem consequências. Podemos perceber nuances negligenciadas, repensar atitudes tomadas.

Assim, partindo dos significados do ensinar, buscamos entender quais as maiores dificuldades na docência dessas mulheres, do campo das Artes Visuais, intencionando penetrar nos bastidores da atuação e do cotidiano profissional. É o que veremos na sequência. 


\section{Quais as maiores dificuldades na docência em Artes Visuais?}

Nas artes, a evocação das memórias pessoais implica a construção de um lugar de resiliência, de demarcações, de individualidade e impressões, nos diz Canton (2009b).

Mas, a memória também é traiçoeira porque ela nos ataca diariamente com sua falta, evidenciada na hesitação, na desistência, no não-dito, no que não foi lembrado (SOUZA; SOUZA, 2015).

No exercício do narrar materializamos nossas memórias, impressões, entendimentos, experiências marcadoras de processos de aprendizagem e criação, dificuldades enfrentadas, medos, superações, conquistas. Pensar sobre as memórias nos leva diretamente à vinculação delas com a identidade, a representação, ao tempo, ao espaço, aos dispositivos e disparadores que possibilitam sua ativação. Seguindo este pensamento, compreendemos que o ato de narrar é um processo de criação contínuo.

Souza; Souza (2015, p.182) trazem a definição de narrativa como a tomada de consciência da própria existência. Para eles "a autobiografia, como dispositivo de pesquisaformação, emerge como campo empírico na contemporaneidade e nos impele a buscar apreender quais relações existem, de fato, entre as narrativas de si, formação e invenção de si”.

Desse modo, ativar as memórias de nossas colaboradoras provocou (re)visitar-se, identificar o fio condutor de suas trajetórias pessoais que incluem também as dificuldades vivenciadas no campo de atuação profissional.

Seguindo essa direção, para a professora Estudiosa não há dificuldades na instituição em que trabalha, "mas se não tivesse toda a estrutura que tem não estaria dando aula".

Sobrevivência diz que suas maiores dificuldades se relacionam ao alunado que não se interessa e ressalta não compreender o que fazem lá e, consequentemente, o que ela faz. Mas, finaliza afirmando que sempre tem os que querem.

Habilidade Interpessoal destaca que suas principais dificuldades são a formação escolar insatisfatória e a desmotivação de estudantes.

A professora Feliz apresenta a interdisciplinaridade como um desejo e uma dificuldade. Pela correria cotidiana que impede os espaços e tempos de troca. Já Pró-ativa evidencia "a desvalorização social e da própria universidade em relação às Licenciaturas que ficam à margem das áreas de conhecimento ditas relevantes e de maior interesse econômico". A professora reforça que é difícil disputar bolsas, incentivos acadêmicos e recursos com as outras áreas, além de trabalhar com aspectos específicos de Artes Visuais ainda se tem que justificar constantemente sua relevância. 
Compartilhando do mesmo posicionamento, a professora Perseverança traz a problemática do descrédito da importância da Arte para o mundo e para as pessoas individualmente.

Positividade registra como maior dificuldade na docência em Artes Visuais as resistências. Ela descreve:

Vivemos um tempo onde a aplicabilidade é mais importante que aprender para fazer algo é única opção. Nesse bojo, cabe ao campo da arte as técnicas, as práticas, negligenciando-o enquanto campo que contribui para expandir os modos de ver, pensar, questionar o mundo, onde as técnicas e as práticas entram, mas não se reduz a apenas isso (Depoimento da professora Positividade).

Ao ser questionada Liberdade apresenta suas maiores dificuldades na docência dizendo o seguinte:

\begin{abstract}
Esta resposta tem variantes, pois trabalhei em vários contextos e níveis de ensino. A falta de espaço específico e a carga horária pequena foram recorrentes na educação básica. Mas, em algumas escolas eu consegui uma sala de artes, ainda que com condições precárias. Mas, a maior dificuldade não é tão imediata, e dela creio que advém todas as outras: a falta de atribuição de importância ao ensino de arte pelos gestores, alguns colegas, estudantes, ou seja, pela sociedade de forma geral. Um problema de mentalidade que pouco valoriza as artes, que é dominante na sociedade brasileira e atinge a escola, relevando o ensino de arte a um papel secundário, sem reconhecimento de seu valor enquanto área de conhecimento. E as consequências disso em termos de políticas de educação, do nível fundamental ao superior, conhecemos bem, de nossas pelejas enquanto arte/educadoras/es. Mesmo assim, os resultados do trabalho apareciam e demarcavam um respeito gradual em cada espaço de atuação, enquanto micropolítica (Depoimento da professora Liberdade).
\end{abstract}

Nas falas das professoras é possível perceber que os destaques são dados a estrutura e condições de trabalho, a desmotivação de estudantes, as lacunas na formação escolar básica, a desvalorização e reconhecimento social da importância da Arte na vida e formação das pessoas, as políticas públicas voltadas ao campo que são ausentes ou estão aquém das necessidades reais dos profissionais envolvidos na área de atuação das Artes Visuais.

Esses aspectos destacados por essas mulheres profissionais das Artes Visuais apresentam leituras, reflexões e a experiência adquirida, ao longo dos anos de trabalho, que se vinculam ao que dizem Chaluh; Camargo (2015, p.188) ao afirmarem que "a documentação da experiência docente supõe tanto uma visão retrospectiva como atual, consiste na sistematização de informações e evidências significativas que deem conta - de forma clara e completa - de atividades já realizadas e/ou em processos".

Diante das dificuldades encontradas no campo de trabalho, buscamos captar dessas professoras sobre a possibilidade hipotética de escolha de outra profissão. Na sequência compreenderemos o que elas dos dizem. 


\title{
4. Se pudesse começar tudo de novo que profissão escolheria?
}

Silva (2015) nos lembra que o método autobiográfico valoriza a subjetividade, as histórias de vida, as trajetórias e a construção dos sujeitos em seus diferentes contextos. Nessa dinâmica se enfrenta o desafio através das palavras das professoras em tornar pública suas opiniões, inquietações, experiências, expectativas e memórias.

Como artesãs da memória essas mulheres rememoram o trajeto vivido, suas escolhas no tempo corrido da vida, constituído pela infância, adolescência, juventude e vida adulta.

É no processo de construção dos memoriais que os caminhos se cruzam entre lembrar e esquecer. A experiência de rever, rememorar, relembrar, narrar é bastante singular em um processo de pesquisa em Arte cujo objeto é você mesmo, sua trajetória de vida e formação, nos dizem Bernardes; Velloso (2015). As autoras ainda afirmam que falar da formação do professor de Arte e do artista é encontrar com essa singularidade e que o processo de "autobio-grafar é aparar a si mesmo com suas próprias mãos; é segurar, resistir ao sofrimento, cortar o que é excessivo, é ajudar a nascer” (BERNARDES; VELLOSO, 2015, p.252).

A questão levantada para nossas colaboradoras sobre se pudesse começar tudo de novo que profissão escolheria, traz subjacente a busca da compreensão da escolha consciente de uma profissão, da identificação com o campo de atuação escolhido, enfim, da realização profissional ou não.

A professora Liberdade responde a esse questionamento dizendo que

\begin{abstract}
Não penso nisso. Meu rumo foi do ensino de arte e procuro a felicidade dentro dele. Mesmo não me sentindo plenamente satisfeita. Será que estaria plenamente satisfeita em outra profissão? Todas têm problemas e dilemas. Gosto do ensino de arte e acho que tem tudo a ver comigo, pois considero importante a dimensão social do trabalho. De todo jeito, qualquer outra profissão que escolhesse, com certeza estaria no universo das artes, minha paixão (Depoimento da professora Liberdade).
\end{abstract}

As professoras Positividade, Habilidade Interpessoal e Sobrevivência nos disseram que escolheriam a mesma profissão. Perseverança também compartilha do mesmo posicionamento e complementa dizendo "quando estou em sala de aula, estou feliz! Realizada! Recompensada!". Da mesma forma a professora Feliz relata que é o que lhe torna realizada. E ainda a professora Estudiosa reforça que tomaria a mesma decisão profissional, porém faria Mestrado e Doutorado mais cedo.

Pró-ativa confessa que as dúvidas surgiram ao longo do tempo e nos diz: 
Já pensei nisto muitas vezes e tive dúvidas se tinha feito as melhores escolhas profissionais no passado. No entanto, hoje tenho certeza que caminhei conforme meu propósito de vida e escolheria as mesmas direções. Sinto-me muito feliz com minhas escolhas. Se pudesse mudar algo, voltaria no tempo e pediria dinheiro para as passagens, aos padres da escola. Com isto teria frequentado o atelier livre de Porto Alegre na adolescência. Acho que com isto teria maior envolvimento com o sistema das artes e teria melhores argumentos para defender minha atuação como professora de artes visuais (Depoimento da professora Pró-ativa).

Ao ouvir suas falas e afirmativas contundentes compreendemos que suas narrativas são vistas como possibilidades de dar visibilidade a essas mulheres, a fim de compreender/apreender os sentidos que estas atribuem à profissão. Meireles (2015) nos lembra que esse caminhar para si, que entrelaça histórias e trajetórias em diferentes espaços e tempos da vida pessoal e profissional, possibilita a cada uma o exercício de falar de si, do que lhes passa e acontece, fazendo ressoar vozes silenciadas e destacando contextos historicamente invisibilizados.

Aproximando-nos, a seguir, do último questionamento apresentado no início desse texto, visamos mergulhar nos sonhos, nas expectativas, nos desejos vislumbrados e alimentados por cada uma de nossas colaboradoras.

\section{Qual seu maior desejo diante do futuro?}

Podemos afirmar que apesar de todas as dificuldades que a vida nos coloca, é necessário perseverar, sonhar, trabalhar para que os sonhos se tornem reais e, novamente, voltar a sonhar porque os sonhos alimentam a existência. Cada época da vida traz consigo descobertas e aprendizagens distintas. (Re)visitar nossas memórias nos permite captar o fio condutor de nossas próprias histórias e construir as narrativas sobre essas memórias permite que elas se materializem e saiam da indiferença colaborando para a ampliação da compreensão, da percepção dos espaços e tempos, estruturas, relações e processos de formação.

Montenegro (2010) nos chama atenção ao afirmar que jamais se deveria pensar a memória ou a percepção como reflexo ou cópia do mundo, mas como atividade, como trabalho ininterrupto de ressignificação do presente.

Diante do questionamento posto às colaboradoras de nossa investigação sobre qual o maior desejo diante do futuro, elas nos responderam o seguinte.

A professora Estudiosa relatou que seu maior desejo diante do futuro é poder sistematizar os trabalhos que foi fazendo e não deu tempo. Revelou a vontade de fazer outro Doutorado e estudar mais Arte. 
Perseverança deseja continuar feliz e realizada como se sente hoje. Já Habilidade Interpessoal ressalta seu desejo de que o mundo seja mais harmônico.

Dar oportunidade para as crianças, dos diferentes povos, aprenderem a ver o mundo com a Arte é o maior desejo da professora Feliz:

Que as sociedades africanas, latino-americanas, estadunidense, europeia, da Oceania e do Brasil tenham que oportunizar as suas crianças aprenderem a ver o mundo com arte. As disputas pelo poder minimizariam e as pessoas iriam viver muito mais felizes e em paz (Depoimento da professora Feliz).

Vários desejos diante do futuro foram elencados pela professora Pró-ativa que nos

disse:

\begin{abstract}
Desejo que os alunos sejam protagonistas em sua formação docente e que não esbarrem em impedimentos burocráticos ou de desvalorização social na atuação como professores. Desejo que o campo das artes visuais fique em constante estado de abertura e diálogo com outras áreas do conhecimento e que se quebre a ideia de que a formação docente deve estar unicamente atrelada a formação acadêmica específica. Ou seja, a formação acadêmica é uma importante etapa de formação docente, mas não é única e exclusiva. Desejo menos reuniões e tempo desperdiçado na frente dos computadores para o registro burocrático de ações pedagógicas. Desejo mais espaço de conversas e oportunidades para estar em convivência com o outro. Desejo que nossos alunos possam se desenvolver espiritualmente e que a universidade não seja um espaço que divide conhecimento acadêmico das vivências cotidianas (Depoimento da professora Pró-ativa).
\end{abstract}

Continuar a ensinar é o foco da professora Sobrevivência. Compartilha do mesmo desejo Positividade. Ela mesma nos revela:

Considerando o campo minado que estamos vivendo na Educação, e mais especificamente, nas ameaças constantes que o campo da Arte recebe, meu maior desejo é que eu possa continuar ensinando Artes Visuais, vendo o reconhecimento e prática em Arte em todas as séries da educação básica, considerando as linguagens Artes Visuais, Dança, Música e Teatro - para que a formação dos sujeitos do futuro seja mais humanizadora (Depoimento da professora Positividade).

Justiça social, distribuição, regulação de recursos e respeito foram os destaques dados pela professora Liberdade. Assim, ela explicita:

Um mundo e um país (minha centralidade) mais justo socialmente, com melhor distribuição e regulação dos recursos, com formas inteligentes de ocupação de territórios, respeito ambiental e respeito a todas as diversidades, naturais e humanas. Utopia ou possibilidade de se utilizar a inteligência humana de forma mais consequente, responsável e generosa? A educação tem papel chave nesse futuro que considero ainda muito longínquo, mas temos que trabalhar nesse horizonte, mesmo que provavelmente não vivamos para ver um início de resultado. Desejos não medem uma crueza realista e se projetam como escapatória da sua crueldade. Desejos são diferentes de projetos... (Depoimento da professora Liberdade). 
Essas narrativas docentes dialogam diretamente com Canton (2009a) ao tratar das narrativas enviesadas contemporâneas que também contam histórias de modo não linear. A autora afirma que elas se compõem a partir de tempos fragmentados, sobreposições, repetições, deslocamentos narrando, mas não necessariamente resolvendo as próprias tramas.

Podemos destacar ainda que as inteligências interpessoal e intrapessoal (GARDNER, 2007) ressaltam com potencialidade nessas mulheres e deixam evidente a força das relações humanas, sobretudo, em tempos onde o individualismo acentuado parece se apresentar como regra única em meio à sociedade contemporânea.

Através das narrativas (re)construídas, (re)visitadas por essas mulheres autoras de suas próprias histórias sobre os significados de sua atuação profissional, suas dificuldades nesse campo, suas escolhas e seus desejos futuros, destacamos a importância de compreender a tessitura de suas trajetórias. Pois, a potencialidade das narrativas autobiográficas como fonte de pesquisa está no fato que a história de vida de uma pessoa pode revelar muito além de simples acontecimentos, caracterizando-se como meio de compreensão dos contextos, dimensões e implicações pessoais que constroem historicamente cada indivíduo na interface consigo mesmo, o outro e o mundo a sua volta (SILVA; MENDES, 2015).

Dialogamos ainda com Candau (2012) ao afirmar que as falhas de memória, os esquecimentos e as lembranças carregadas de emoção são sempre vinculados a uma consciência que age no presente. Porque a memória organiza os traços do passado em função dos engajamentos do presente e logo por demandas do futuro. A lembrança não contém a consciência, mas a evidencia e manifesta, é a consciência mesma que experimenta no presente a dimensão de seu passado.

\section{Referências}

BERNARDES, Rosvita Kolb; VELLOSO, Luciana Mendes. Experiências biográficas: reconhecer-se incompleto. In: (Auto)Biografias e documentação narrativa: redes de pesquisa e formação. Salvador: EDUFBA, 2015, p.243-257.

BUENO, Kátia Maria Penido. Construção de habilidades: trama de ações e relações. Belo Horizonte: Autêntica, 2007.

CANDAU, Joël. Memória e Identidade. São Paulo: Contexto, 2012.

CANTON, Katia. Narrativas Enviesadas. São Paulo: Editora WMF Martins Fontes, 2009a. 
CANTON, Katia. Tempo e Memória. São Paulo: Editora WMF Martins Fontes, 2009b.

CORDEIRO, Telma de S.C.; MELO, Márcia M.de O.; RAMOS, Kátia M. da C.

Desenvolvimento profissional docente na universidade: formação continuada didáticopedagógica como objeto de investigação, reflexão e intervenção. In: RAMOS, Kátia M. da C.; VEIGA, Ilma A. P. Desenvolvimento profissional docente: currículo, docência e avaliação na educação superior. Recife: Ed.Universitária da UFPE, 2013, p.21-38.

DELORY-MOMBERGER, Christine. Narrativa de Investigação profissional: um dispositivo de pesquisa-formação sob a forma de uma escrita implicada. In: SOUZA, Elizeu Clementino de (Og.). (Auto)Biografias e documentação narrativa: redes de pesquisa e formação. Salvador: EDUFBA, 2015, p.161-171.

DOMINGO, José Contreras. Profundizar narrativamente la educación. In: SOUZA, Elizeu Clementino de (Og.). (Auto)Biografias e documentação narrativa: redes de pesquisa e formação. Salvador: EDUFBA, 2015, p.37-61.

FREIRE, Paulo. Pedagogia da Autonomia: saberes necessários à prática educativa. São Paulo: Paz e Terra, 1996.

GARDNER, Howard. Inteligências Múltiplas: a teoria na prática. Porto Alegre: Editora Artmed, 2007.

MEIRELES, Mariana Martins de. Entrevista narrativa e hermenêutica de si: fonte de pesquisa (auto)biográfica e perspectiva de análises. In: SOUZA, Elizeu Clementino de (Og.). (Auto)Biografias e documentação narrativa: redes de pesquisa e formação. Salvador: EDUFBA, 2015, p.285-296.

MONTENEGRO, Antonio Torres. História, Metodologia, Memória. São Paulo: Contexto, 2010 .

POUPART, Jean; DESLAURIERS, Jean-Pierre; GROULX, Lionel-H.; LAPERRIÈRE, Anne; MAYER, Robert; PIRES, Álvaro P. A Pesquisa Qualitativa: enfoques epistemológicos e metodológicos. Petrópolis: Vozes, 2008.

SAMPAIO, Carmen Sanches; RIBEIRO, Tiago. Documentação narrativa de experiências pedagógicas: escritas de si e formação docente. In: SOUZA, Elizeu Clementino de (Og.). (Auto)Biografias e documentação narrativa: redes de pesquisa e formação. Salvador: EDUFBA, 2015, p.105-125.

SILVA, Arlete Vieira da. O gênero memorial na pesquisa (auto)biográfica: concepções e percursos metodológicos. In: SOUZA, Elizeu Clementino de (Og.). (Auto)Biografias e documentação narrativa: redes de pesquisa e formação. Salvador: EDUFBA, 2015, p.201-217.

SILVA, Francisco das Chagas Rodrigues da; MENDES, Bárbara Maria Macedo. Narrativas de professores de Geografia: a escrita de si como projeto de conhecimento e formação. In: PORTUGAL, Jussara Fraga; CHAIGAR, Vânia Alves Martins (Orgs.). Ensino e pesquisa em educação geográfica: memórias, histórias de vida e narrativas docentes. Salvador: EDUFBA, 2015. 
SILVA, Maria Betânia e. Escolhas e decisões profissionais: memórias de professoras. In: $28^{\circ}$ Encontro Associação Nacional de Pesquisadores em Artes Plásticas, 2019, Goiania. Anais do XXVIII Encontro Nacional da Associação Nacional de Pesquisadores em Artes Plásticas. Goiania: ANPAP, 2019. v. 1. p. 57-71.

SILVA, Maria Betânia e. Revisitando memórias: percursos de vida-formação. In: $27^{\circ}$ Encontro da associação Nacional de Pesquisadores em Artes Plásticas, 2018, São Paulo. Anais do $27^{\circ}$ Encontro da ANPAP. São Paulo: Instituto de Artes/UNESP, 2018. v. 1. p. 1-13.

SILVA, Maria Betânia e. Memórias acionadas: ações de (re)existir em Artes Visuais (ISSN 2526-7949). In: Utopias Pedagógicas em Artes como Gesto de (Re)Existência - VI Congresso Internacional Sesc de Arte/Educação, 2018, Recife. Utopias Pedagógicas em Artes como Gesto de (Re)Existência - Vi Congresso Internacional Sesc de Arte/Educação? Anais. Recife: SESC Pernambuco, 2018. v. 1. p. 519-525.

SILVA, Maria Betânia e. Memórias de Professoras de Artes Visuais. In: $26^{\circ}$ Encontro da ANPAP - Memórias e Inventações, 2017, Campinas. ANAIS DO XXVI ENCONTRO DA ASSOCIAÇÃO NACIONAL DE PESQUISADORES EM ARTES PLÁSTICAS: MEMÓRIA̧S E INVENTAÇÕES. Campinas: ANPAP/PUC Campinas, 2017. v. 1. p. 745755.

SOUZA, Rodrigo Matos de; SOUZA, Elizeu Clementino de. O fenômeno da escrita (Auto)biográfica: localização teórico-históricas. In: SOUZA, Elizeu Clementino de (Og.). (Auto)Biografias e documentação narrativa: redes de pesquisa e formação. Salvador: EDUFBA, 2015, p.173-184. 